Domingues, H, Valentin, TJ \& Miranda, GMC. (2020). Sócio-environmental responsibility: the case of a cosmetics industry in the interior of Minas Gerais, Brazil. Research, Society and Development, 9(7):1-18. e359973056.

\title{
Responsabilidade socioambiental: o caso de uma indústria de cosméticos do interior de
} Minas Gerais, Brasil

Socio-environmental responsibility: the case of a cosmetics industry in the interior of Minas Gerais, Brazil

Responsabilidad socioambiental: el caso de una industria cosmética en el interior de Minas Gerais, Brasil

Recebido: 08/03/2020 | Revisado: 09/03/2020 | Aceito: 08/05/2020 | Publicado: 17/05/2020

\section{Homero Domingues}

ORCID: http://orcid.org/0000-0001-9237-7371

Faculdade Doctum de João Monlevade, Brasil

E-mail: profhomerodomingues@gmail.com

Talles Jefferson Valentim

ORCID: https://orcid.org/0000-0003-2210-505X

Faculdade Doctum de João Monlevade, Brasil

E-mail: tallesjeffersonvalentim@gmail.com

Gustavo Martins do Carmo Miranda

ORCID: http://orcid.org/0000-0001-7341-5651

Universidade Federal de Minas Gerais, Brasil

E-mail: gustavmcm@gmail.com

\section{Resumo}

Nas últimas décadas, questões relacionadas à Responsabilidade Socioambiental e ao crescimento sustentável nas organizações estão sendo constantemente debatidas pela sociedade. Este estudo teve como objetivo identificar os principais projetos sociais e ambientais em uma indústria de cosméticos, bem como compreender a percepção dos moradores e beneficiários locais em relação às ações desenvolvidas pela empresa. A relevância da pesquisa está no fato da responsabilidade socioambiental ser assunto de interesse: de diversos públicos envolvidos com as organizações, sejam eles funcionários, clientes, fornecedores, gestores ou sociedade local. Para a realização do estudo foram realizadas pesquisas bibliográficas em livros e artigos sobre o tema, além de um estudo de 
caso em uma indústria de cosméticos do interior de Minas Gerais, com a realização de entrevista com o gestor da empresa e a aplicação de questionário com os moradores da cidade em que está inserida a indústria de cosméticos. Por meio dessas pesquisas foi possível entender que a preservação do lucro da instituição está diretamente relacionada aos investimentos em sustentabilidade apresentados pela empresa. Além disso, foi possível entender a percepção da comunidade local quanto aos projetos socioambientais implantados pela organização.

Palavras-chave: Sustentabilidade; Ambiente organizacional; Crescimento sustentável; Comunidade local.

\begin{abstract}
In recent decades, issues related to Social and Environmental Responsibility and sustainable growth in organizations have been constantly debated by society. This study aimed to identify the main social and environmental projects in a cosmetics industry, as well as to understand the perception of local residents and beneficiaries regarding the actions developed by the company. The relevance of the research lies in the fact that social and environmental responsibility is a matter of interest to various publics involved with organizations, whether employees, customers, suppliers, managers or local society. To carry out the study were conducted bibliographic searches in books and articles on the subject, as well as a case study in a cosmetics industry in the interior of Minas Gerais, with interviews with the manager of the company and the application of a questionnaire with residents of the city where the cosmetics industry is located. Through these researches it was possible to understand that the preservation of the institution's profit is directly related to the sustainability investments presented by the company. In addition, it was possible to understand the perception of the local community regarding the social and environmental projects implemented by the organization.
\end{abstract}

Keywords: Sustainability; Organizational environment; Sustainable growth; Local community.

\title{
Resumen
}

En las últimas décadas, la sociedad debate constantemente temas relacionados con la responsabilidad social y ambiental y el crecimiento sostenible en las organizaciones. Este estudio tuvo como objetivo identificar los principales proyectos sociales y ambientales en una industria cosmética, así como comprender la percepción de los residentes y beneficiarios 
locales en relación con las acciones desarrolladas por la empresa. La relevancia de la investigación radica en el hecho de que la responsabilidad socioambiental es un tema de interés para varias audiencias involucradas con las organizaciones, ya sean empleados, clientes, proveedores, gerentes o la sociedad local. Para llevar a cabo el estudio, se realizaron búsquedas bibliográficas en libros y artículos sobre el tema, además de un estudio de caso en una industria cosmética en el interior de Minas Gerais, con una entrevista con el gerente de la empresa y la aplicación de un cuestionario con Los residentes de la ciudad donde opera la industria cosmética. A través de estas encuestas fue posible comprender que la preservación de las ganancias de la institución está directamente relacionada con las inversiones en sostenibilidad presentadas por la empresa. Además, fue posible comprender la percepción de la comunidad local con respecto a los proyectos socioambientales implementados por la organización.

Palabras clave: Sostenibilidad; Ambiente organizacional; Crecimiento sostenible; Comunidad local.

\section{Introdução}

Nos últimos anos, as questões referentes à Responsabilidade Socioambiental têm ganhado espaço nas mídias e, sobretudo nas ações das organizações e de seus gestores. Porém, percebe-se que no Brasil as ações empresariais ainda são incipientes no que se refere à sustentabilidade.

Para uma organização ser considerada sustentável, é necessário que atenda às suas necessidades do presente, sem comprometer os recursos que garantirão o desenvolvimento e o bem-estar das gerações futuras. Deve, sobretudo, preocupar-se com todas as variáveis e pessoas envolvidas em seus processos, trabalhando para atingir as metas econômicas, sem perder de vista os objetivos da sociedade em geral, notadamente a preservação do meio ambiente.

A visão clássica da empresa pode incorporar em seu planejamento estratégico as questões socioambientais, além da obrigação legal, eleva os custos e reduz o lucro das empresas. Esse posicionamento é uma estratégia de curto prazo que não se sustenta diante do conceito de empresa socialmente responsável. Para que haja perpetuação da política de responsabilidade socioambiental, trabalha-se com a visão de lucro a longo prazo, como forma de alcançar os objetivos empresariais (Borger, 2013).

Diante do exposto, questiona-se: como uma empresa pode visar ao lucro e, 
concomitantemente, implementar medidas de responsabilidade socioambiental? Nesse sentido, o presente artigo tem como objetivo geral identificar os principais projetos sociais e ambientais implantados por uma indústria de cosméticos, bem como compreender a percepção dos moradores e beneficiários locais em relação às ações desenvolvidas pela indústria e entender como esses investimentos geram lucros para a organização. Além disso, os objetivos específicos desse estudo são: caracterizar os diferentes projetos sociais e ambientais desenvolvidos pela indústria de cosméticos; descrever a percepção dos moradores e dos beneficiários quanto aos resultados gerados pelos projetos; identificar como a empresa consegue conciliar responsabilidade socioambiental com a preservação de seu lucro; além de apresentar para a empresa os resultados da pesquisa e propor algumas ações para continuidade dos projetos. Portanto, a responsabilidade socioambiental é um assunto do interesse de diversos públicos, o que atribui relevância a este estudo. Todos os indivíduos ligados às organizações - sejam eles funcionários, clientes, fornecedores, gestores e sociedade local são beneficiados, direta ou indiretamente, por estudos que visem a embasar e fomentar ações empresariais voltadas à preservação do meio ambiente e pelo desenvolvimento de projetos sociais.

Para atingir os objetivos propostos neste trabalho, a pesquisa divide-se em duas etapas. A primeira tem uma abordagem qualitativa, de caráter exploratório, para aprofundamento do tema por meio do levantamento bibliográfico em livros e artigos especializados no tema. Essa parte também é constituída por entrevista semiestruturadas com o principal gestor da empresa e por observação de dados secundários em alguns órgãos governais responsáveis pela área de Responsabilidade Socioambiental. A segunda etapa tem caráter descritivo e uma abordagem quantitativa, com o fim de coletar dados sobre a percepção da sociedade local acerca dos projetos socioambientais implementados por uma indústria de cosméticos do interior de Minas Gerais.

O artigo encontra-se dividido da seguinte forma: após essa breve introdução, é abordada o referencial teórico que apresenta autores que fazem considerações a respeito da contextualização histórica da responsabilidade socioambiental, do conceito de responsabilidade socioambiental empresarial, dos benefícios e vantagens da implantação da responsabilidade sócio empresarial dentro das organizações, além da abordagem sobre indicadores de desempenho. A próxima seção faz menção à caracterização da organização onde será realizado o estudo de caso. Em seguida, apresenta-se a metodologia utilizada na realização do trabalho. Logo após, aborda-se a pesquisa e a análise dos dados apurados durante a realização do trabalho. Encerra-se o trabalho com as considerações finais. 


\section{Contextualização Histórica da Responsabilidade Socioambiental}

De acordo com Dias (2017), os consumidores começaram a ter consciência das questões socioambientais durante a segunda metade do século XX, essa conscientização ocorreu ao mesmo tempo em que cresceram de forma considerada as denúncias a respeito dos impactos ambientais que as atividades organizacionais estavam causando no meio ambiente.

Reis \& Medeiros (2007) acrescentam que, a Responsabilidade Social das Empresas (RSE) teve o seu início nos anos de 1960 nos Estados Unidos da América (EUA), motivada pela busca por maior consciência de segmentos da sociedade em relação à responsabilidade das empresas na preservação do meio ambiente e dos direitos dos consumidores.

Diante de um contexto econômico caracterizado por uma rígida postura dos consumidores que possuem uma percepção direcionada à expectativa de interagir com organizações que sejam éticas, com uma imagem institucional de crédito com o mercado, e com empresas que sejam ecologicamente responsáveis, têm-se desenvolvido nas empresas uma visão voltada para a gestão da responsabilidade social (Tachizawa, 2004).

No Brasil, no ano de 1998, a Confederação Nacional da Indústria (CNI) elaborou a Declaração de Princípios da Indústria para o Desenvolvimento Sustentável. Essa declaração continha normas que visavam ao crescimento empresarial de forma simultânea ao desenvolvimento social e ambiental. A publicação do documento do CNI, como considera Dias (2017) foi considerada como um grande passo para que as empresas colocassem em seu planejamento maneiras de realizar as suas atividades de uma forma que não gere um impacto negativo no meio ambiente e contribua para o desenvolvimento da sociedade em que está inserida.

\subsection{Responsabilidade Socioambiental Empresarial}

De acordo com Tachizawa (2002), a responsabilidade socioambiental quando implementada nas organizações agregam valor para seus clientes e são fatores que servem como diferencial competitivo para a organização. Nesse sentido as organizações devem implantar a responsabilidade socioambiental em suas atividades e fazer com que todos os envolvidos e impactados pelas ações percebam as atitudes que equilibram o crescimento econômico com o desenvolvimento da sociedade e do meio ambiente.

Percebe-se entre as empresas com destaque em ações de responsabilidade socioambiental benefícios como uma melhor imagem institucional, melhor aproveitamento 
dos recursos e acesso a mercado de capitais, etc. Benefícios esses que podem ajudar em uma melhor competitividade no mercado, formados, na maioria das vezes, por uma elevada rivalidade entre os competidores. Sendo assim, Lilian Aligleri; Luiz Aligleri \& Krunglianskas (2009), mencionam a competitividade no novo contexto empresarial e segundo os autores:

A revolução tecnológica e o mundo cada vez mais globalizado estão gerando transformações e, consequentemente, um novo contexto competitivo empresarial. Rapidez nas informações, maior concorrência e comunicação instantânea ocasionaram uma nova realidade para as organizações. Preço, produto de qualidade, notável serviço ao cliente e controle de custos são condições mínimas para a sobrevivência das empresas e isoladamente não impulsionam o crescimento da organização (Aligleri, Aligleri \& Kruglianskas, 2009, p. 4).

Esses autores também revelam que o macroambiente tem impostos novos desafios para as organizações, tais como: maior valorização por comportamentos ecologicamente corretos, busca por qualidade de vida no trabalho, postura ética e diversidade da força de trabalho devido aos novos valores sociais, cultura e estilo de vida.

Diante do cenário atual, com o aumento da competitividade e a preocupação das empresas em manter os clientes e/ou conquistar o mercado consumidor, torna-se necessária a adoção de práticas de responsabilidade socioambiental, o que pode trazer resultados positivos para as organizações.

Responsabilidade Socioambiental diz respeito à postura adotada por uma empresa no sentido de criar melhoria contínua para a sociedade e o meio ambiente. Empresas de todos os segmentos, por meio da aplicação da responsabilidade socioambiental em suas atividades buscam formas de ressarcir todo o público envolvido e que será afetado pelos processos das organizações, com práticas que contribuam com a melhoria contínua do meio ambiente e consequentemente tragam uma melhor qualidade de vida para as pessoas (Lacerda \& Moura, 2016).

Pode inferir que as empresas que não traçarem metas estratégicas em seus negócios para conquistar a competitividade, não sobreviverão em meio àquelas organizações que visam ao alinhamento da teoria com a prática. Nota-se que, em mundo onde a disputa por um espaço no mercado está cada vez mais acirrada, apenas as empresas que realmente implantarem estratégias que de fato contribuíram para colocar em prática o exercício da responsabilidade socioambiental, irão ter continuidade no mercado empresarial. Desse modo, consideramos de 
modo semelhante ao que afirma Tachizawa (2004), é fundamental que essas empresas sejam socialmente responsáveis e adotem estratégias para um desenvolvimento sustentável e que atendam aos aspectos legais.

\subsection{Desenvolvimento Sustentável}

Segundo Dias (2017), o desenvolvimento sustentável dentro das organizações é representado pelas dimensões econômica, social e ambiental. Levando-se em conta a dimensão econômica, ser uma organização sustentável é obter o retorno esperado através do investimento realizado na implantação da organização. Já na dimensão social a organização deve adotar formas de proporcionar para todos os envolvidos no contexto organizacional melhores condições de vida. Por fim, a dimensão ambiental aponta que a organização deve colocar em prática ações que contribuam para o desenvolvimento ambiental, deve obter uma postura de responsabilidade ambiental.

Donaire (2016) corrobora que, o desenvolvimento sustentável vai além da antiga visão que as organizações tinham a respeito do motivo de sua existência, que era simplesmente auferir lucro através da produção de bens e serviços, com a nova visão, para ser considerada uma empresa sustentável, a organização além de obter lucro deve preocupar-se com a forma como modifica o meio ambiente e a sociedade ao qual está inserida.

Para Tachizawa (2007), a busca pela sustentabilidade e consequentemente o desenvolvimento sustentável por parte das organizações está se tornando uma realidade para o mundo dos negócios, além de ser essencial para o crescimento econômico empresarial, a busca pelo desenvolvimento sustentável é fator de vantagem competitiva para a organização. $\mathrm{O}$ autor acrescenta que, questões sociais e ambientais, em equilíbrio com as questões econômicas são essenciais para o êxito e a sobrevivência dos negócios.

Para tanto, as empresas podem se valer de indicadores que auxiliam na identificação do grau de responsabilidade de suas empresas. Na literatura sobre o assunto encontram-se várias ferramentas de indicadores de sustentabilidade que serão abordadas a seguir.

\subsection{Indicadores de Responsabilidade Socioambiental}

Segundo Martins \& Candido (2008), os indicadores de responsabilidade socioambiental (RSA) são instrumentos utilizados pelas empresas a fim de direcionar suas estratégias em busca da vantagem competitiva. Os indicadores constituem importantes 
critérios para orientar a gestão e o planejamento de políticas e ações que podem ser desenvolvidas pelas empresas.

Nas literaturas sobre o tema, encontram-se diversos modelos de avaliação de RSA que podem ser utilizados pelas organizações e que são adotados em vários países. Para tanto, muitas organizações utilizam desses indicadores que acompanham e controlam as práticas e estratégias empresariais para obter competitividade e lucratividade.

O tema indicador de desempenho em RSA, no Brasil, teve o seu início, em 1997, com lançamento do modelo de Balanço Social, por Betinho, do Instituto Brasileiro de Análises Sociais e Econômicas (IBASE), considerado um dos primeiros modelos utilizados no Brasil. Na mesma época, em 1998, houve também a criação do Instituto Ethos de Responsabilidade Social, pelo empresário Oded Grajew (Rabelo \& Silva, 2011).

Segundo Godoy et al. (2007), o Balanço Social leva em consideração os principais indicadores de desempenho econômico, social e ambiental das empresas. Ele pode ser considerado um meio de ampliar a comunicação com seus diversos públicos de interesse: acionistas, consumidores/clientes, comunidade vizinha, funcionários, fornecedores, governo, organizações não governamentais, mercado financeiro e sociedade.

O Instituto Ethos de Responsabilidade Social utiliza de um conjunto composto de quatro dimensões, sendo: visão e estratégia; governança e gestão; ambiental; e social. Os Indicadores Ethos têm como foco avaliar o quanto a sustentabilidade e a responsabilidade social têm sido incorporadas nos negócios, auxiliando a definição de estratégias, políticas e processos (Botelho et al, 2015).

Segundo Botelho et al. (2015), outro indicador muito utilizado em nível mundial, refere-se aos relatórios da Global Reporting Initiative (GRI), uma organização sem fins lucrativos, criada em 1997 por meio de uma ação conjunta da Coalizition for Environmentally Responsible (CERES) e do Programa das Nações Unidas para o Meio Ambiente (PNUMA). A finalidade dessa Organização Não Governamental (ONG) é contribuir para a melhoria dos relatórios de sustentabilidade publicados pelas empresas com maior qualidade, rigor e aplicação global, a fim de tornar os relatórios internacionalmente harmônicos. Esses relatórios devem ser elaborados com total transparência, abrangência, relevância, neutralidade, exatidão, objetividade e facilidade de compreensão.

O GRI utiliza de uma guia de apresentação com os principais indicadores de desempenho organizado pelas dimensões: econômica, social e ambiental (Global Reporting Initiative, 2015).

O Global Reporting Initiative (GRI) é formado por uma rede de peritos e 
representantes de diversos setores da sociedade (empresas, organizações não governamentais, peritos, agências governamentais, entre outros), presentes em mais de 40 países ao redor do mundo. Esses profissionais participam em grupos de trabalho e órgãos de governança do GRI e determinam as diretrizes do GRI para a realização de relatórios de sustentabilidade com a constante participação de diversas partes interessadas (Hourneaux, Corrêa \& Gomes, 2010).

Considerando um índice como simplesmente um indicador de alta categoria, leva-se em conta o Índice de Sustentabilidade Empresarial (ISE), também como um indicador de Responsabilidade Social. De acordo com Botelho et al. (2015), o ISE avalia o desempenho das 150 empresas com as ações mais negociadas na BOVESPA - Bolsa de Valores, Mercadorias e Futuros. Essas empresas devem demonstrar desempenho em relação à gestão sustentável no Brasil e ser referência para investidores financeiros no mundo todo, que estão em busca de aplicações em empresas socialmente responsáveis, sustentáveis e rentáveis.

Outro indicador, utilizado por empresas brasileiras e de outros países refere-se ao Grupo de Reflexão e Apoio à Cidadania Empresarial - GRACE. Trata-se de uma associação, sem fins-lucrativos e exclusivamente dedicada à promoção da Responsabilidade Social Corporativa. O GRACE foi fundado em Fevereiro de 2000 por um conjunto de empresas e atualmente reúne mais de 150 empresas, das mais variadas dimensões e setores de atividade, empenhadas em aprofundar o seu papel no desenvolvimento social das pessoas e das organizações e esse grupo tem como missão: refletir, promover e desenvolver a responsabilidade social corporativa em Portugal (Grace, 2014).

Para a presente pesquisa, pretende-se utilizar o indicador GRACE, pela simplicidade e facilidade de aplicação em pequenas e médias empresas. Ibid (2014) trata das seguintes dimensões de Responsabilidade Social: a) Responsabilidade na gestão; b) Responsabilidade pelos colaboradores; c) Responsabilidade na cadeia de valor; d) Responsabilidade pela comunidade; e) Responsabilidade pelo ambiente.

\section{Caracterização da Organização}

No ano de 1989, a empresa BioExtratus Cosméticos Naturais deu início às suas atividades, na cidade de Belo Horizonte - Minas Gerais, quando os proprietários procuravam um diferencial na área de cosméticos, e além disso, buscavam produtos capazes de atender às expectativas de todos os níveis de consumidores, tanto em qualidade quanto em preço. No início do ano de 1991 surge a marca Extratus - Produtos Naturais, a primeira empresa a apostar na utilização do óleo de tutano em cosméticos capilares. 
Em meados de 1997, a empresa passava por uma revolução tecnológica, seus processos, mesmo que ainda timidamente, deixavam de serem artesanais para serem tecnológicos. As vendas aumentavam consideravelmente e a marca passava a se tornar referência para uma grande gama de clientes. Em 1998, a Extratus Produtos Naturais passou a se chamar BioExtratus Cosméticos Naturais.

Atualmente, superando os 25 anos de atuação no mercado, oferecendo emprego diretamente para mais de 500 pessoas, a empresa BioExtratus é uma organização que apresenta grande grau de satisfação por parte de seus clientes e demais envolvidos. É uma empresa que preza o crescimento sustentável e busca meios de levar benefícios a todos os públicos que são impactados por suas ações.

A BioExtratus tem como missão oferecer ao consumidor, cosméticos de alta qualidade e preço acessível, produzidos de forma sustentável, com ética e responsabilidade socioambiental. Crescer junto com nossos fornecedores, parceiros comerciais e colaboradores, ampliando a participação no mercado, através de parcerias consolidadas. Já a visão da organização é ser referência nacional na fabricação sustentável de produtos cosméticos, reconhecidos pela sua qualidade, que combinam natureza e tecnologia. Além disso, a empresa possui os seguintes valores: comportamento ético, inovação tecnológica, primazia em saúde, segurança no trabalho, meio ambiente e serviço de qualidade.

\section{Metodologia}

Quanto à natureza trata-se de uma pesquisa aplicada. Para atingir os objetivos propostos neste trabalho, a pesquisa subdividiu-se em duas etapas. A primeira etapa consiste na abordagem qualitativa, de caráter exploratório, para aprofundamento do tema em livros e artigos especializados. Segundo Lakatos \& Marconi (1991), a pesquisa bibliográfica trata-se do levantamento, seleção e documentação de toda bibliografia já publicada sobre o assunto que está sendo pesquisado em livros, enciclopédias, revistas, jornais, folhetos, boletins, monografias, teses e dissertações. Essa parte, também foi constituída por entrevista com o gestor da empresa responsável pelos projetos socioambientais.

Já a segunda etapa teve caráter descritivo e uma abordagem quantitativa, com a coleta de dados primários, entre os moradores da cidade e beneficiários dos projetos socioambientais da empresa, a fim de investigar as percepções e conhecimentos acerca desses projetos. Com referência a esse levantamento como meio da pesquisa descritiva, Gil (2002) comenta que, além da multiplicidade de tipos, os levantamentos desenvolvem-se ao longo de várias fases, 
abrangendo a elaboração do instrumento de coleta de dados, pré-teste do instrumento, seleção da amostra, coleta e verificação dos dados, análise e interpretação dos dados e apresentação dos resultados.

A pesquisa foi desenvolvida em uma indústria de cosméticos do interior de Minas Gerais. Qualitativamente foi realizada uma entrevista como orienta Barbetta (2011) com o principal gestor da instituição. Quantitativamente foi efetuada uma pesquisa descritiva, com uma amostragem por julgamento ${ }^{1}$.

\section{Práticas de Responsabilidade Socioambiental na Indústria de Cosméticos}

Foi realizada uma entrevista com o principal gestor da instituição, com a aplicação de um questionário com perguntas estruturadas. Para tanto, foi utilizado o modelo de indicador de sustentabilidade baseado no GRACE (2014), a partir de perguntas confeccionadas com opções de resposta evidenciando a existência ou não de critérios de indicadores de RSA. No caso de não aplicação da pergunta, para a empresa pesquisada, utilizou-se a opção "não se aplica". O referido indicador utilizado trata das seguintes dimensões: a) Responsabilidade na gestão; b) Responsabilidade pelos colaboradores; c) Responsabilidade na cadeia de valor; d) Responsabilidade pela comunidade; e) Responsabilidade pelo ambiente. A partir da entrevista, pôde-se constatar que a BioExtratus Cosméticos Naturais possui grande preocupação nos impactos que suas ações causam para a comunidade local e ao meio ambiente.

Para tanto, no que se refere à dimensão responsabilidade na gestão, a instituição tem em seu planejamento estratégico princípios éticos que norteiam as atividades realizadas, bem como avalia e monitora a satisfação de todas as partes interessadas. Além disso, busca partilhar as informações sobre suas práticas e indicadores econômicos sociais e ambientais por meio de comunicações on-line.

No que tange à dimensão responsabilidade pelo ambiente, a instituição investe em procedimentos voltados para a redução do consumo de energia, da poluição e do consumo de água, além de desenvolver iniciativas para sensibilizar os colaboradores, fornecedores e clientes para as questões ambientais.

\footnotetext{
${ }^{1}$ Neste tipo de amostra, os elementos escolhidos são aqueles julgados como típicos da população que se deseja estudar (Barbetta, 2011).
} 
No tocante à dimensão responsabilidade pela comunidade, a instituição contribui para o desenvolvimento da sociedade local por meio de investimentos em ações que visam a melhorar a condição de vida das pessoas, seja por meio de patrocínios e donativos, ou pelo desenvolvimento de projetos sociais que envolvem toda a sociedade.

Já na dimensão responsabilidade pelos colaboradores, a instituição acredita que o desenvolvimento dos colaboradores, por meio do incentivo à educação, à saúde e pelo reconhecimento da capacidade profissional e pessoal das pessoas é fator preponderante para a satisfação dos funcionários no desempenho de suas atividades.

Com a relação à dimensão responsabilidade na cadeia de valor, a BioExtratus Cosméticos Naturais realiza a gestão da sua cadeia de suprimentos, de modo a incentivar seus stakeholders na busca pela qualidade e honestidade, por meio de contratos e negócios que não prejudiquem nem um lado nem o outro. Além disso, conta com ferramentas para registrar reclamações, tanto de consumidores e clientes, quanto de fornecedores.

Levando-se em conta todas essas dimensões, a instituição acredita que os investimentos realizados em responsabilidade socioambiental agregam valor à marca BioExtratus e geram uma vantagem competitiva em relação aos seus concorrentes, o que garante a maximização do lucro da empresa, além de contribuir para o desenvolvimento da sociedade e do meio ambiente ao qual está inserida.

\subsection{Percepção da Comunidade Local em Relação à Responsabilidade Socioambiental da}

\section{Empresa BioExtratus}

Foi realizada uma pesquisa descritiva a fim investigar a percepção da sociedade local com relação aos projetos sociais e ambientais desenvolvidos pela empresa. Para tanto, foi utilizada uma amostra, por acessibilidade, composta por 136 respondentes com características heterogêneas.

Quando questionado aos entrevistados sobre o significado de RSA, cerca de 98,5\% mostrou conhecimento do significado do termo. O que demonstra a importância do tema para a Sociedade local e para a empresa.

No que se refere à percepção dos entrevistados sobre os projetos sociais implantados pela empresa, 94,9\% dos respondentes disseram que a organização possui projetos sociais. Deste modo, considera-se que a sociedade local percebe os projetos sociais de autoria da empresa e os impactos positivos gerados por tais projetos. Por outro lado, no tocante aos projetos ambientais implantados pela organização, 75,7\% dos respondentes consideram que a 
empresa possui projetos ambientais. Já os outros 24,3\% dos entrevistados não souberam responder quando questionados se a empresa possui projetos ambientais. Diante disso, constata-se que a empresa deve trabalhar os seus projetos ambientais para que uma maior parte da sociedade perceba os projetos ambientais implantados na comunidade pela organização.

Quando solicitados aos respondentes para listarem os projetos sociais e ambientais desenvolvidos pela indústria pesquisada, foram identificados os seguintes, conforme consta no quadro $\left(n^{\circ} 1\right)$ a seguir (Quadro 1$)$ :

Quadro 1: Projetos Sociais e Ambientais percebidos pelos entrevistados.

\begin{tabular}{|l|l|}
\hline \multicolumn{1}{|c|}{ PROJETOS SOCIAIS } & \multicolumn{1}{c|}{ PROJETOS AMBIENTAIS } \\
\hline Fundação BioExtratus & Estação de tratamento de afluentes \\
\hline Bateria Colibri & Fontes renováveis de energia \\
\hline Passarela BioExtratus & Gerenciamento de resíduos sólidos \\
\hline Incentivo à educação & Reaproveitamento da água \\
\hline Utilização da mão de obra local & Recuperação de nascentes \\
\hline Apoio à prática de esportes e eventos culturais & Reposição da mata nativa \\
\hline Não utilização de mão de obra infantil & \\
\hline
\end{tabular}

Fonte: Elaborado pelos autores.

Nota-se que $98,5 \%$ dos entrevistados têm conhecimento da definição de responsabilidade socioambiental e, desse modo sabem identificar os projetos sociais e ambientais desenvolvidos pela instituição, além de perceberem como estes contribuem para o desenvolvimento da comunidade local.

Salienta-se que, dentro dos projetos sociais listados pelos 129 entrevistados que disseram que a indústria possui projetos sociais, a maior lembrança como projeto social desenvolvido pela empresa foi o projeto Bateria Colibri, sendo mencionado por $86,1 \%$ do público que reconhece algum projeto de cunho social desenvolvido pela BioExtratus.

Quanto aos projetos ambientais percebidos pelos 103 entrevistados que responderam que a empresa possui projetos ambientais, a maior lembrança foi o projeto Estação de tratamento de afluentes, sendo lembrado por $40,78 \%$ do público que reconhece que a empresa apresenta projetos ambientais.

$86 \%$ dos entrevistados classificam a empresa como muito atuante no cenário da responsabilidade socioambiental. Porém, 60,3\% dos respondentes não têm conhecimento sobre como a empresa define quais as ações e projetos serão implantados visando a atender às necessidades da sociedade. Estes acreditam que a instituição, antes de elaborar os projetos 
(CC BY 4.0) | ISSN 2525-3409 | DOI: http://dx.doi.org/10.33448/rsd-v9i7.3056

socioambientais, participa de discussões envolvendo os líderes da comunidade, para saber quais as áreas necessitam de apoio.

Durante a aplicação da entrevista foi questionado se a comunidade necessita de algum projeto social ou ambiental que a organização ainda não atende $61 \%$ dos entrevistados responderam que sim. Segundo esses entrevistados, a comunidade ainda é carente de alguns projetos sociais e ambientais que poderiam ser implantados pela empresa. Sendo assim, foi solicitado aos $61 \%$ dos entrevistados exemplos de projetos sociais e ambientais que poderiam ser atendidos pela empresa. Diante dessa resposta, foram identificados os seguintes projetos sociais e ambientais que podem ser implantados pela instituição, conforme consta no quadro $\left(n^{\circ} 2\right)$ abaixo:

Quadro 2: Projetos Sociais e Ambientais sugeridos pelos entrevistados.

\begin{tabular}{|l|l|}
\hline \multicolumn{1}{|c|}{ PROJETOS SOCIAIS } & \multicolumn{1}{c|}{ PROJETOS AMBIENTAIS } \\
\hline $\begin{array}{l}\text { Incentivo à educação para todos os membros } \\
\text { da comunidade }\end{array}$ & $\begin{array}{l}\text { Projeto de reciclagem que envolve toda a } \\
\text { comunidade }\end{array}$ \\
\hline $\begin{array}{l}\text { Apoio à saúde para a comunidade e } \\
\text { investimento em lazer para os idosos }\end{array}$ & $\begin{array}{l}\text { Projeto de preservação do meio ambiente } \\
\text { extensivo à comunidade }\end{array}$ \\
\hline Projetos de apoio à arte e dança & \multicolumn{1}{c}{-} \\
\hline
\end{tabular}

Fonte: Elaborado pelos autores.

Com base na entrevista realizada, percebe-se que a BioExtratus Cosméticos Naturais contribui de forma assertiva para o desenvolvimento da comunidade local. Nota-se ainda que, 95,9\% dos entrevistados possuem uma imagem positiva da instituição, o que torna fator preponderante para a ótima relação entre a instituição e a sociedade. Contudo, $88,7 \%$ dos entrevistados acreditam que a instituição poderia investir ainda mais em áreas como a saúde da população e a conscientização de toda a comunidade nos assuntos como: reciclagem, coleta seletiva e preservação do meio ambiente.

\section{Considerações Finais}

Por meio deste estudo foi possível entender que atualmente, a maximização e preservação do lucro de toda e qualquer empresa, seja ela de pequeno, médio ou grande porte, também podem estar relacionados com as ações e projetos socioambientais que são implantados pela instituição. Nesse sentido, entende-se que o problema apresentado nesse trabalho foi entendido e solucionado, inicialmente, por meio da entrevista realizada com o 
gestor da BioExtratus Cosméticos Naturais e por meio da percepção da comunidade local, a respeito da contribuição que os projetos socioambientais implantados pela instituição trazem para a sociedade.

Os objetivos do presente trabalho foram alcançados a partir de pesquisas bibliográficas realizadas a respeito do tema e por meio da entrevista com o gestor da instituição e, posteriormente, com pessoas da comunidade local.

Quanto às contribuições proporcionadas por essa pesquisa, entende-se que o tema Responsabilidade Socioambiental está em crescente evolução, desse modo, qualquer empresa que almeje a continuidade e a lucratividade do seu negócio, pode fazer uso dessa pesquisa para entender quais contribuições o investimento em projetos socioambientais podem trazer para as empresas. Além disso, por meio deste estudo, torna-se possível para a sociedade entender as contribuições que a responsabilidade socioambiental, quando de fato implantada pelas empresas podem trazer para a comunidade.

Sendo o tema Responsabilidade Socioambiental relativamente recente quando tratado pelas pequenas e médias empresas, sugere-se o aprofundamento e sequenciamento do estudo, como forma de manutenção e evolução das práticas sustentáveis na indústria pesquisada, bem como a proposta de desenvolvimento dos projetos sociais e ambientais sugeridos pela sociedade local.

\section{Referências}

Aligleri, L, Aligleri, LA \& Kruglianskas, I. (2009). Gestão Socioambiental: responsabilidade e sustentabilidade do negócio. São Paulo: Atlas.

Barbetta, PA. (2011). Estatística aplicada às ciências sociais. Florianópolis: UFSC.

Borger, FG. (2013). Responsabilidade social empresarial e sustentabilidade para a gestão empresarial. Acesso em 15 de março, em: https://www.ethos.org.br/cedoc/responsabilidadesocial-empresarial-e-sustentabilidade-para-a-gestao-empresarial/\#.xi5rdyhkjiu.

Botelho, KT. (2015). Indicadores de sustentabilidade empresarial: um estudo exploratório. Revista Eletrônica Interdisciplinar, 8 (2), 104-16.

Dias, R. (2017). Gestão Ambiental: Responsabilidade Social e Sustentabilidade. 3ed. São 
Paulo: Atlas.

Donaire, D. (2016). Gestão Ambiental na Empresa. 2ed. São Paulo: Atlas.

GIL, AC. (2002). Como elaborar projetos de pesquisas. São Paulo: Atlas.

Global Reporting Initiative. (2015). Elaboração de relatórios de sustentabilidade, 2015. https://www.globalreporting.org/resourcelibrary/GRIG4-Part1-Reporting-Principles-andStandard-Disclosures.pdf.

Godoy, M, Pfitscher, ED, Gasparetto, V \& Limongi, B. (2007). Balanço Social: convergências e divergências entre os modelos do IBASE, GRI e Instituto ETHOS. In: Trabalho apresentando no I Congresso UFSC de Controladoria e Finanças, Florianópolis, SC, Brasil, 1, 25-9.

GRACE. (2014). Guia Responsabilidade Social nas Pequenas e Médias Empresas. http://www.grace.pt/conteudos/00/04/00/00/GUIA-RS-NAS-PME_SITE_9985.pdf.

Hourneaux, FJr, Corrêa, HL \& Gomes, CM. (2010). Indicadores de sustentabilidade: em busca de um modelo de integração e de diferenciação estratégica para a gestão empresarial. Trabalho apresentado no XXXIV Encontro da Anpad, Rio de Janeiro, RJ, Brasil, 34,1-15.

Lacerda, AS \& Moura, D. (2016). A Responsabilidade Socioambiental Como Estratégia de Competitividade para as Organizações de Contemporaneidade. Trabalho apresentado no XII Congresso de Nacional Excelência em Gestão, Rio de Janeiro, RJ, Brasil, 12,1-16.

Lakatos, EM \& Marconi, MA. (1991). Fundamentos da Metodologia Científica. 3.ed. rev. e ampl. São Paulo: Atlas.

Martins, MF \& Candido, GA. (2008). Indicadores de Desenvolvimento Sustentável para Localidades: uma proposta metodológica de construção e análise. In: Candido, G.A. Desenvolvimento Sustentável e Sistemas de Indicadores de Sustentabilidade: formas de aplicação em contextos geográficos diversos e contingências especificas. Campina Grande: 
UFCG.

Pereira, AS, Shitsuka, DM, Parreira, FJ \& Shitsuka, R. (2018). Metodologia da pesquisa científica. [e-book]. Santa Maria. Ed. UAB/NTE/UFSM. Acesso em: 15 maio 2020.

Disponível em:

https://repositorio.ufsm.br/bitstream/handle/1/15824/Lic_Computacao_MetodologiaPesquisa-Cientifica.pdf?sequence $=1$.

Rabelo, NS \& Silva, CE. (2011). Modelos de indicadores de responsabilidade socioambiental corporativa. Revista Brasileira de Administração Científica, 2 (1),5-30.

Reis, CN \& Medeiros, LE. (2007). Responsabilidade social das empresas e balanço social. São Paulo: Atlas.

Tachizawa, T. (2002). Gestão Ambiental e Responsabilidade Social Corporativa: estratégias de Negócios Focadas na Realidade Brasileira. São Paulo: Atlas.

Tachizawa, T. (2004). Gestão Ambiental e Responsabilidade Social Corporativa: Estratégias de Negócios Focadas na Realidade Brasileira. 2.ed. rev. e ampl. São Paulo: Atlas.

Tachizawa, T. (2007) Organizações Não Governamentais e Terceiro Setor: Criação de Ongs e Estratégias de Atuação. 3.ed. São Paulo: Atlas.

\section{Porcentagem de contribuição de cada autor no manuscrito}

Homero Domingues $-40 \%$

Thalles Jefferson $-40 \%$

Gustavo Martins do Carmo Miranda - 20\% 